\title{
Mid-Frequency Ventilation: A Viable Option for Lung Protection?
}

Prevention of lung injury caused by mechanical ventilation has rightfully assumed high priority in the support of patients with acute lung injury. The pathophysiology of ventilator-induced lung injury is complex, with both mechanical stresses and diverse non-mechanical background factors (such as position, vascular flows, $\mathrm{F}_{\mathrm{IO}_{2}}$, and body temperature) determining the magnitude of its expression. ${ }^{1}$ Under predisposing background conditions, repeated overstretching of fully aerated alveoli and force amplification at the interface of closed and open tissues may result in release of inflammatory mediators, intolerable shearing stresses, vascular disruption, and small airway damage from incessant opening and closing of unstable lung units. The alveolar pressures that determine whether ventilator-induced lung injury will be caused or avoided include the maximum and minimum values encountered at the extremes of the tidal cycle (plateau pressure and total PEEP) and the difference between them, often designated as the driving pressure. Since the landmark ARDS Network study, which confirmed that lower tidal volumes $\left(\mathrm{V}_{\mathrm{T}} 6 \mathrm{~mL} / \mathrm{kg}\right.$ of ideal body weight) are associated with better outcomes than high ones $(12 \mathrm{~mL} / \mathrm{kg}$ of ideal body weight $),{ }^{2}$ there has been an understandable preoccupation with limiting the tidal excursions of pressure and volume so as to reduce the lungs' exposure to damaging tidal cycles. Some authors have pointed out the difficulty of identifying safe lower threshold limits for $\mathrm{V}_{\mathrm{T}}$ and plateau pressure in the setting of acute lung injury, ${ }^{3}$ which for any given patient might co-depend on the integrity of right ventricular function. ${ }^{4}$

In this issue of Respiratory CARE, Mireles-Cabodevila and colleagues present experimental work demonstrating the feasibility of significantly reducing $\mathrm{V}_{\mathrm{T}}$ and excursions of tidal pressures by using ventilator frequencies higher than those customarily targeted. 5 This method, previously described in conceptual fashion by these authors as midfrequency ventilation (MFV), ${ }^{6}$ uses algorithm-adjusted pressure controlled ventilation over a frequency range of $\sim 50-70$ breaths/min. Because alveolar pressure during

Dr Marini has disclosed no conflicts of interest.

Correspondence: John J Marini MD, Regions Hospital MS11203B, 640 Jackson Street, St Paul, MN 55101-2595. E-mail: john.j.marini@ healthpartners.com.

DOI: $10.4187 /$ respcare. 03687 pressure controlled ventilation rises and falls quasi-exponentially toward the airway pressure extremes of the tidal cycle, ${ }^{7} \mathrm{~V}_{\mathrm{T}}$ declines as progressively increasing frequency allows less time for alveolar pressures to build and fall to their fixed airway pressure targets. Lower $\mathrm{V}_{\mathrm{T}}$ means lower plateaus, higher total PEEP, and reduced driving pressure. What could be better than that?

Caution is advisable. As exemplified by the HIFI trial in neonates 25 years $\mathrm{ago}^{8}$ and by the more recently failed OSCILLATE trial of high-frequency oscillation in adults, ${ }^{9}$ limiting $\mathrm{V}_{\mathrm{T}}$ cannot alone assure better outcome. One of the more appealing explanations for the disappointing results of those clinical trials relates to the higher mean alveolar pressures and their hemodynamic consequences that higher frequencies entail. The afterload to the right ventricle, often dysfunctional in ARDS and pumping against high pulmonary vascular resistance, ${ }^{10}$ tends to increase with mean

See the Original Study on Page 1619

alveolar pressure. Furthermore, the efficiency of ventilation, expressed as the ratio of total minute ventilation to $\mathrm{P}_{\mathrm{aCO}}$, also suffers as the dead-space fraction inevitably rises with the small $\mathrm{V}_{\mathrm{T}}$ associated with high-frequency oscillatory ventilation due to a disproportionate concomitant rise in the series (anatomic) dead-space component. Whatever the mode, using higher cycling frequencies augments the intensity of exposure to any damaging tidal force (in the language of physics, the mechanical work delivered per unit time, or power increases). Finally, as frequency rises, intracycle repair time following overstretch is also abbreviated. ${ }^{11}$ In a nutshell, minute volume should not be ignored when the object is to reduce the risk of iatrogenic injury.

Similar issues regarding altered ventilatory efficiency and hemodynamics may well apply at the rates associated with MFV, which are closer to conventional range. The data of Mireles-Cabodevila and colleagues, ${ }^{5}$ collected in animals with mild lung injuries, raise some concerns. In comparison to conventional pressure controlled ventilation, the algorithmoptimized MFV $V_{\mathrm{T}}$ was lower by $\sim 20 \%$, whereas the MFVoptimized minute volume needed to maintain a similar $\mathrm{P}_{\mathrm{aCO}_{2}}$ was greater than the control by a much higher percentage. Heart rate also increased rather impressively during MFV, even though cardiac output and mean vascular pressures changed very little. The cause for this tachycardia is not 


\section{Mid-Frequency Ventilation for Lung Protection}

evident; however, alveolar pressure during MFV was modestly higher due to the auto-PEEP generated at rapid frequencies. This pilot study of MFV, conducted in an anesthetized animal model of acute lung injury, is a convincing demonstration that such an approach is feasible for those specific experimental conditions and for the limited duration of observation. Its performance in other models, over longer periods of observation, and in more severely injured lungs cannot be assumed. As the authors point out, translation directly to clinical practice cannot be advised on the strength of sound theory and these data alone.

Should reducing tidal pressures and $\mathrm{V}_{\mathrm{T}}$ below current recommendations prove beneficial (and currently, that issue is still widely open), exploration of a higher frequency range with an approach like MFV would be one of several ways to implement the desired $V_{T}$ reduction. Acceptance of the hypercapnia attendant to reducing $\mathrm{V}_{\mathrm{T}}$ at conventional frequency would be another, and use of extracorporeal gas exchange a third. ${ }^{12}$ The nature and severity of the clinical problem would dictate the approach to be tried first, and as always, the patient's integrated cardiorespiratory response would decide its value.

Whether MFV is eventually deployed and proves its worth at the bedside, the work presented here by Mireles-Cabodevila and colleagues ${ }^{5}$ provides interesting preclinical data motivated by a strongly mechanistic rationale. It is precisely this type modeling and testing of a clinical problem, once so prevalent in the science of respiratory care, that tests our assumptions, helps develop a solid base for designing clinical studies, and provides insights for improving care delivery. Unfortunately, although such experiments in applied physiology are still much needed, they are rapidly vanishing from our nation's funded research agenda.

John J Marini MD

Professor of Medicine University of Minnesota Minneapolis/St Paul, Minnesota

\section{REFERENCES}

1. Slutsky AS, Ranieri VM. Ventilator-induced lung injury. N Engl J Med 2013;369(22):2126-2136.

2. The Acute Respiratory Distress Syndrome Network. Ventilation with lower tidal volumes as compared with traditional tidal volumes for acute lung injury and the acute respiratory distress syndrome. N Engl J Med 2000;342(18):1301-1308.

3. Hager DN, Krishnan JA, Hayden DL, Brower RG. Tidal volume reduction in patients with acute lung injury when plateau pressures are not high. Am J Respir Crit Care Med 2005;172(10):1241-1245.

4. Jardin F, Vieillard-Baron A. Is there a safe plateau pressure in ARDS? The right heart only knows. Intensive Care Med 2007;33(3):444447.

5. Mireles-Cabodevila E, Chatburn RL, Thurman TL, Zabala LM, Holt SJ, Swearingen CJ, Heulitt MJ. Application of mid-frequency ventilation in an animal model of lung injury: a pilot study. Respir Care 2014;59(11):1619-1627.

6. Mireles-Cabodevila E, Chatburn RL. Mid-frequency ventilation: unconventional use of conventional mechanical ventilation as a lungprotection strategy. Respir Care 2008;53(12):1669-1677.

7. Marini JJ, Crooke PS 3rd, Truwit JD. Determinants and limits of pressure-preset ventilation: a mathematical model of pressure control. J Appl Physiol 1989;67(3):1081-1092.

8. The HIFI Study Group. High-frequency oscillatory ventilation compared with conventional mechanical ventilation in the treatment of respiratory failure in preterm infants. N Engl J Med 1989;320(2): 88-93.

9. Ferguson ND, Cook DJ, Guyatt GH, Mehta S, Hand L, Austin P, et al. High-frequency oscillation in early acute respiratory distress syndrome. N Engl J Med 2013;368(9):795-805.

10. Mekontso Dessap A, Charron C, Devaquet J, Aboab J, Jardin F, Brochard L, Vieillard-Baron A. Impact of acute hypercapnia and augmented positive end-expiratory pressure on right ventricle function in severe acute respiratory distress syndrome. Intensive Care Med 2009;35(11):1850-1858.

11. Vlahakis NE, Hubmayr RD. Cellular stress failure in ventilatorinjured lungs. Am J Respir Crit Care Med 2005;171(12):1328-1342.

12. Bein T, Weber-Carstens S, Goldmann A, Müller T, Staudinger T, Brederlau J, et al. Lower tidal volume strategy $(\approx 3 \mathrm{~mL} / \mathrm{kg})$ combined with extracorporeal $\mathrm{CO}_{2}$ removal versus 'conventional' protective ventilation $(6 \mathrm{~mL} / \mathrm{kg})$ in severe ARDS: The prospective randomized Xtravent-study. Intensive Care Med 2013;39(5):847-856. 